\title{
Perception and Verbalization of Somatic (Bodily) Codes of Culture in the Conditions of Bilingualism and Biculturalism
}

\section{Восприятие и вербализация соматических (телесных) кодов культуры в условиях билингвизма}

\section{Svetlana Shlyakhova}

Dr. in Philology, Head of the Chair of Foreign Languages and Public Relations

\section{Светлана Шляхова}

доктор филологических наук, зав. кафедрой иностранных языков и связей с общественностью

\footnotetext{
E-mail: shlyahova@mail.ru orcid.org/0000-0002-5636-4837

Scopus Author ID: 55934110900

Researcher ID: D-1271-2017
}

Perm National Research Polytechnic University

29, Komsomolsky prospect,

Perm, Russian Federation
Пермский начиональный исследовательский политехнический университет Комсомольский проспект, 29, Пермь, Российская Федерация

Original manuscript received May 10, 2018

Revised manuscript accepted September 15, 2018

\section{ABSTRACT}

The article is devoted to the perception and verbalization of somatic (bodily) codes of culture in the conditions of bilingualism and biculturalism. The ability of Komi-Permian bilinguals to identify somatic codes of their culture was revealed. The experiment was conducted in the form of an individual questionnaire in the Komi-Permyak district of the Perm region of the Russian Federation. The experimental material was created using the method of generalized portrait. Two images of real girls (Komi-Permyak and Russian) were superimposed on each other with the help of Face Morph program. "Artificial» 
person is obtained as a result, which combines somatics representatives of two non-related ethnic groups (Indo-European and Finno-Ugric). Three images (Russian, Komi-Permyak and "artificial» faces) were presented to respondents. It is established that the Komi-Permians recognize faces somatic code well. In the conditions of bilingualism and biculturalism somatic codes of culture in the consciousness of Komi-Perm change more slowly than in Russian. 62\% of Komi-Permyaks choose the face of their ethnic group. The Komi-Permians "artificial» person likes least of all (9\% of respondents). $29 \%$ of the KomiPerm choose Russian face. Interpretation of the code is a subjective process and often depends on personal perception in the control groups of Russians. Russians choose an "artificial» person is 4 times more often than the KomiPermians. Choose more often (52\%), Komi-Permyatskiy face the Russians, who constantly live in the Permian Komi district. Russians who are not affected by Komi-Permyak culture choose Komi-Permyak face in $42 \%$ of cases. Russians Komi-Perm district choose the Russian face 6 times less likely $(8,7 \%)$ than face of Komi-Permyaks (52\%). Komi-Permians choose a Russian face 3 times more often (29\%) than the Russians themselves. The analysis of verbal responses showed that the physicality in the minds of the Komi-Perm with mental and moral characteristics, not physical. These characteristics are actual bodily identifiers for the Komi-Permians.

Key words: bilingualism, somatic (bodily) code, culture code, Komi-Permyak, Finno-Ugric, perception, ethnic identity, ethnic identification.

\section{Введение}

Актуальность исследования кодов культуры обусловлена, с одной стороны, проблемой утраты или размывания этнический идентичности в условиях глобализации, с другой, - формированием глобальных кодов культуры (Чернышева, 2016), которые влекут за собой утрату национальной идентичности, формирование биэтничности и общероссийской идентичности (Скоробогатая, 2008: 10), проблемы бикультурализма и мультикультурализма (Арутюнов, 1978; Benet-Martínez, 2005; Русских, 2013; Вигель, 2017).

Наступившая эпоха глобализации приводит к стиранию границ между этносами, культурами, ментальностями, что грозит утратой национальной самобытности многих народов. Проблема утраты этнической идентичности характерна и для коми-пермяков - финноугорский этнос, компактно проживающий на территории Пермского края Российской Федерации. 
Особо важными вопросы этнической идентичности становятся в условиях билингвизма и бикультурализма в исторически полиэтнических регионах (Barth, 1969; Root, 1992; Sollars, 1996; Trimble, 2000; Phinney, 2003; Weinreich, 2003; Губогло, 2003; Выскочил, 2005; Попова, 2006; Kyuchukov, 2016; Giuseppina, 2017), к которым относится Пермский край.

Острота поставленной проблемы возрастает в условиях однополярного двуязычия, которое, в отличие от полилингвизма (биполярного двуязычия), обладает большей силой воздействия на ассимилятивные процессы. В этих условиях сохранение этнической идентичности становится все более трудной задачей для так называемых малых этносов, в том числе и для коми-пермяков.

Низкая этническая самооценка и низкая лояльность коми-пермяков к собственной этничности, деформация этнического сознания приводит к дефициту национальной идентичности, разрушению позитивного образа собственного этноса. Как следствие - слабая мотивация к изучению родного языка, слабая выраженность исторических и культурных детерминант национального самосознания (историческое прошлое и традиции народа, обычаи и нормы поведения, культура), отсутствие повсеместной практики использования родного языка, нежелание коми-пермяков говорить, читать и писать на родном языке, который не является социально престижным. Все попытки сохранить коми-пермяцкий язык и культуру оказываются практически безрезультатными, поскольку не вытекают из объективной потребности этноса.

Исследования относительно возможности возрождения национальных языков и культур приводят к выводам о том, что это возрождение происходит только тогда, когда возникает мотивация (идеологическая, социально-психологическая, экономическая) их использования, возрастает их престиж и, соответственно, укрепляется приверженность к ним. Коми-пермяцкий этнос слабо мотивирован на приверженность к родному языку. В этом контексте исследования сохранности кодов культуры представляется особенно важными.

Кроме того, сегодня остро встает проблема межнациональных конфликтов, которые приводят к серьезным экономическим и социальным проблемам. Включенность коми-пермяков в мировой 
Восприятие и вербализаиия соматических (телесных) кодов...

финно-угорский контекст происходит при помощи этнических общественных организаций. Политические спекуляции на национальном вопросе внутри общественных организаций, этнополитическая ангажированность языковой политики со стороны финно-угорского мира могут привести к обострению национальных отношений, расколу внутри этноса, втягиванию этноса в этнополитические конфликты. Актуальность темы обусловлена необходимостью решения коммуникационных проблем полиэтничных регионов, в том числе необходимостью создания научно обоснованной концепции, на базе которой можно будет моделировать языковую политику, направленную на гармонизацию отношений в полиэтничных регионах. Для этого необходимы исследования коми-пермяцкого языка и культуры в контексте семиотики, когнитологии, этнопсихологии, культурологии и пр.

Новизна работы заключается в том, что автором статьи предложена оригинальная методика идентификации культурных кодов в сознании билингвов. Впервые исследуется способность билингвов идентифицировать соматические коды в условиях бикультурализма.

Исследование кодов культуры чрезвычайно значимо, поскольку это «формальные и материальные средства для кодирования одного и того же содержания, сводимого в целом к «картине мира», к мировоззрению данного социума» (Толстой, 1995; Толстая, 2007).

Под кодами культуры мы понимаем набор культурных архетипов, характеризующих идентичность историко-культурного типа личности, социальной группы и пр. (Глоссарий, 1998; Культурология, 2010). Коды культуры соотносятся с архетипами и фиксируют наивные представления о мироздании (Красных, 2001), они универсальны, но их проявление, реализация и значение в культуре этноса национально детерминированы.

На сегодняшний день какой-либо общепринятой классификации культурных кодов не существует. Пока не существует и общепризнанного единого основания для классификации кодов культуры.

Обобщая позиции исследователей относительно кодов культуры (Эко, 1998; Chandler, 1999; Красных, 2001; Гудков, 2004; Danesi, 2007 и др.), отметим, что в той или иной категории все ученые выделяют соматический (телесный), пространственный, 
природно-ландшафтный, временной (темпоральный), предметный (артефактный, вещный), гастрономический, биоморфный, духовный и др. как базовые коды культуры.

«Человек одновременно идентифицирует себя с различными общностями: биологическими (от расовых до кровнородственных), территориальными (с присущими им иерархиями), конфессиональными, языковыми, социальными (классовыми, сословными, кастовыми и т.п.), культурными. Возникает иерархия идентичностей», причем индивид «при соотнесении себя с определенными общностями выделяет наиболее важные для него актуальные идентификации...» (Беликов, 2001). В.В. Красных определяет код культуры, «как «сетку», которую культура «набрасывает» на окружающий мир, членит, категоризует, структурирует и оценивает его» (Красных, 2001). Мы пытались обнаружить наличие / отсутствие такой сетки в сознании комипермяков-билингвов.

Предмет исследования - соматический код культуры естественный (Эко, 1998) реальный (Толстой, 199; Гудков, 2004) интерпретационный (Chandler, 1999) код восприятия и узнавания (Эко, 1998).

Соматический код культуры является самым древним, поскольку именно с постижения самого себя человек осмысляет и интерпретирует окружающий его мир (антропоморфизм как способ познания мира). Соматические коды исследуются в когнитивной лингвистике, культурологии, прагматике, социологии (Turner, 1984; Мазалова, 2001; Geurts, 2002; Csordas, 2002; Леонтьева, 2003; Якушкина 2003; Кабакова, 2005; Завалишина, 2005; Гудков, 2007; Багаутдинова, 2007; Olza Moreno, 2009; Горды, 2010; Щирова, 2011; Башкатова, 2014). «В освоении мира человек совершил путь от самого себя к самому себе же» (Красных, 2001: 6).

Наряду с термином соматический код в научной литературе используются термины телесный (Гудков, 2007: 9), антропоморфный (Багаутдинова, 2007: 21), физиолого-соматический (Леонтьева, 2003: 9-15) код.

Цель исследования - выявление способности комипермяков-билингвов идентифицировать, «прочитывать», ощущать соматические коды своей культуры. 
Восприятие и вербализаиия соматических (телесных) кодов...

Эта задача тем более интересна, поскольку «базовые коды культуры, которые зачастую трудны для выявления и рефлексии, требуют гораздо больше времени для созревания, по-видимому, не одно столетие; меняются же они в крайне замедленном темпе» (Аванесова, 2015: 35). Кроме того, «прочтение и интерпретация кода представляют собой субъективный процесс и зависят от личностного восприятия и особенностей содержания и бытования социально-культурных практик» (Симбирцева, 2016).

Вербальные реакции, полученные в ходе эксперимента, дают возможность доступа к языковому сознанию носителей языка и описанию их языковой картины мира.

\section{Материал и методика исследования}

Для исследования был проведен социолингвистический эксперимент по восприятию и вербализации соматического кода культуры. Эксперимент проводился в виде анкетирования.

Современные исследования обычно включают онлайнанкетирование, однако для коми-пермяков данный вид опроса представляются затруднительными по многим причинам. Во-первых, коми-пермяки являются преимущественно сельским этносом (в Коми-пермяцком округе только один город Кудымкар - с населением около 30000 человек) с невысоким уровнем компьютеризации. Во-вторых, ситуация однополярного билингвизма требовала изучения языкового сознания, которое менее всего подвержено влиянию русского языка, т.е. деревенских малообразованных жителей старшего поколения, у которых отсутствуют компьютеры. В связи с этим эксперимент проводился в виде индивидуального анкетирования в населенных пунктах Комипермяцкого округа.

Поскольку эксперимент проводился в полевых условиях при большой численности экспериментальной группы, то целесообразным было использование метода случайного отбора с применением процедуры рандомизации. Случайное распределение респондентов в экспериментальную и контрольную группы позволило снизить вероятность отбора испытуемых одного типа. Размер выборки - 234 человека, генеральная совокупность 109642 человек. Всего было получено 234 анкеты, включающие 102 вербальные реакции. 
Выборки информантов были сбалансированы по следующим социальным факторам: гендер, возраст, этническая принадлежность, место проживания.

Вербальные реакции респондентов обрабатывались методом компонентного (семного) анализа. В полученных от респондентов вербальных реакциях выделялись компоненты значения (семы); также производился количественный анализ сем.

В качестве экспериментальной группы билингвов-носителей кодов культуры выступают коми-пермяки - основное население Коми-Пермяцкого округа, расположенного на северо-западе Пермского края Российской Федерации. Коми-пермяцкий язык относится к пермской ветви финно-угорской подсемьи уральских языков и состоит в близком родстве с коми-зырянским (Республика Коми, РФ) и удмуртским (Удмуртия, РФ) языками. Около 90\% комипермяков свободно владеют русским языком. Относительно комипермяков можно говорить о ситуации однополярного двуязычия, т.е. преимущественного влияния русского языка на коми-пермяцкий. В качестве контрольной группы выступили русские, проживающие в Коми-Пермяцком округе (испытывают влияние коми-пермяцкой культуры) и в Перми (влияние коми-пермяков минимально).

Для создания экспериментального материала использовался также метод обобщенного портрета. При помощи программы Face Morph был составлен обобщенный портрет русской и комипермячки («два в одном флаконе»). Метод обобщенного портрета, разработанный Ф. Гальтоном в 1878 г., сегодня широко применяется в антропологии для выявления общих черт в сериях портретных изображений. Суть метода - накладывание изображений друг на друга при помощи разных техник (фотонегативы или компьютерные программы).

«С помощью такого суммирования мы приходим к типологической характеристике выборки. При этом чем больше у нас выборка, тем больше индивидуальных особенностей может полностью исчезнуть из суммарного результата; происходит своеобразный «отрыв» суммарного образа от индивидуальных признаков» (Маурер, 2006: 9).

Наложив друг на друга два изображения реальных людей (коми-пермячки (рис. 1 в) и русской (рис. 1 а), мы получили «искусственное» лицо (рис. 1 б), совмещающее соматику 
представителей не родственных индоевропейского и финноугорского этносов. Таким образом для предъявления респондентам был получен следующий стимульный материал (рис. 1).

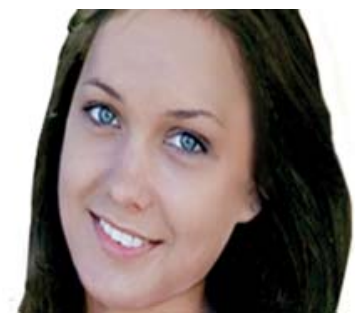

а. Стимул 1: русская

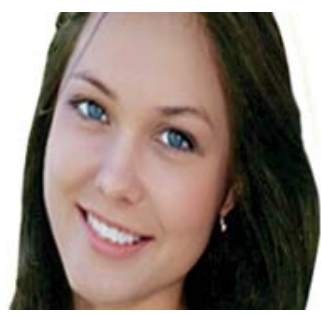

б. Стимул 2: обобщенный портрет

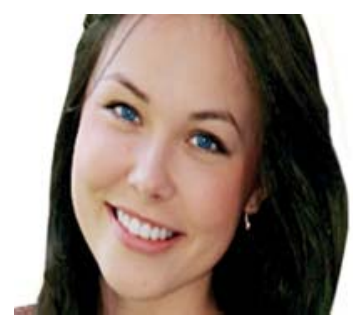

в. Стимул 3: коми-пермячка

Рис. 1. Стимульный материал

\section{Структура выборки}

Всего опрошено 234 респондента: 176 человек разного пола, возраста, образования, национальности (русские и коми-пермяки), которые родились и постоянно проживают на территории города Кудымкара и поселений Коми-пермяцкого округа (Пешнигорт, Кочёво, Мамоново, Архангельское, Нёльсино, Чазёво, Пелым, Крохалева, Юксеево, Юрла, Верх-Юсьва, Егорово, Попова, Юсьва, Ошиб) и 58 человек (русских по национальности), проживающих в Перми. Этническая принадлежность респондентов: 136 респондентов $(58,1 \%)$ - коми-пермяки (экспериментальная группа) и $40(17,1 \%)$ русские, живущие в Коми-пермяцком округе, $58(24,8 \%)$ - русские, живущие в Перми (контрольные группы). Состав респондентов Коми-пермяцкого округа сбалансирован по принципу урбанизированности: в равной мере представлен жителями города Кудымкар (50\%) и села Пешнигорт $(27,8 \%)$ и другие деревни (22,2\%). Этническая принадлежность респондентов Коми-пермяцкого округа: 136 респондентов (77,3\%) - комипермяки, 40 - русские $(22,7 \%)$. Гендерный состав респондентов: $62 \%$ - женщины, 38\% - мужчины. В эксперименте приняли участие респонденты от 10 до 72 лет (рис. 2).

\section{Эксперимент 1. Восприятие и узнавание соматического кода}

Внешность посылает определенные коммуникативные сигналы, которые могут быть проигнорированы или неверно дешифрованы 
воспринимающим. Респондентам показывался стимульный материал (рис. 1) и предлагалось выбрать девушку, которая им больше нравится. Результаты выбора «нравится больше всех» представлены на рисунке 3.

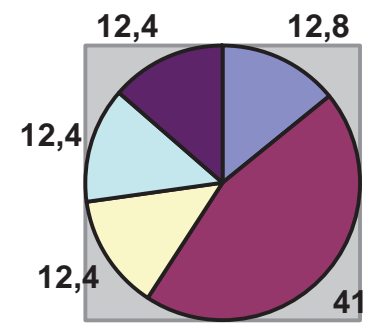

\begin{tabular}{|l|}
\hline$\square$ до 17 \\
$\square 18-25$ \\
$\square 26-40$ \\
$\square 41-55$ \\
$\square 56+$ \\
\hline
\end{tabular}

Рис. 2. Возрастная структура выборки: Коми-пермяикий округ (\%)

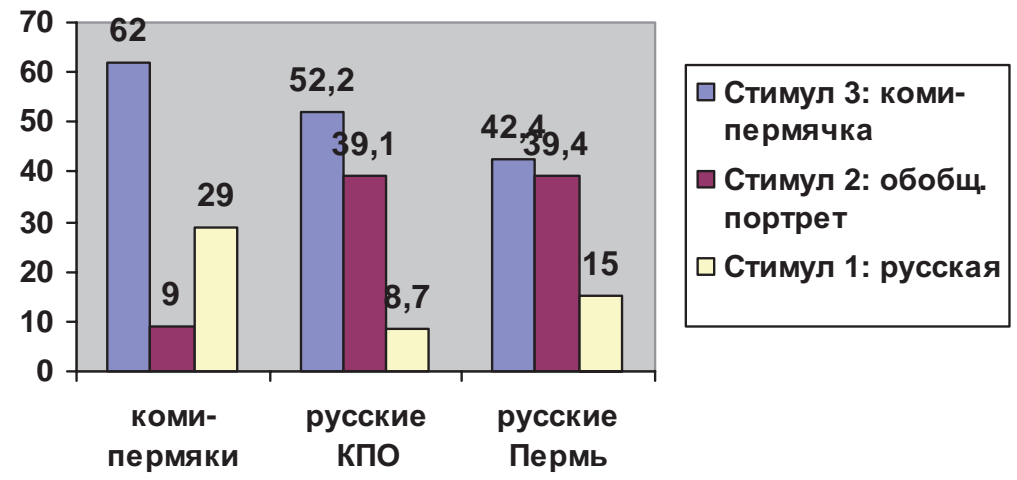

Рис. 3. Реакциии на стимул 1-3: «нравится больше всех» (\%)

Экспериментальная группа: коми-пермяки в подавляющем большинстве (62\% всех респондентов) выбирают «родное» лицо (стимул 3); менее всего коми-пермякам нравится «искусственное» (стимул 2) лицо (9\%); 29\% коми-пермяков выбираю русское лицо (стимул 1).

Гендерные предпочтения коми-пермяков представлены на рисунке 4.

Этническую соматику мужчины и женщины предпочитают приблизительно в равных пропорциях (47\% и 53\% соответственно), однако женщины в 2 раза чаще, чем мужчины, выбирают русское (63\% против 37\%) и «искусственное» (64\% против 33\%) лица. 
Таким образом, коми-пермяцкие мужчины несколько больше ценят этнически близкий тип внешности, чем женщины.

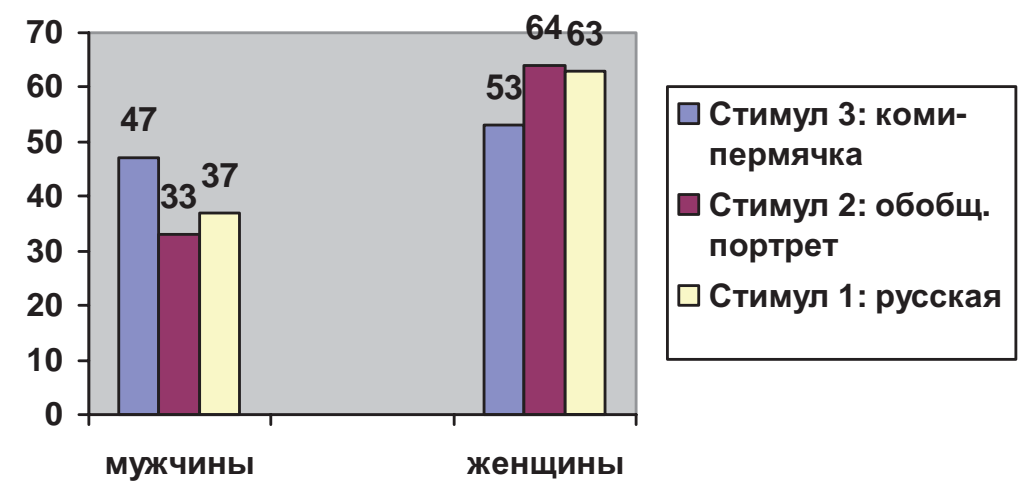

Рис. 4. Гендерные реакиии на стимул 1-3: «нравится больще всех», (\%)

Контрольные группы: русские в 4 раза чаще выбирают «искусственное» лицо (стимул 2) по сравнению с коми-пермяками. Обобщенные портреты имеют одну особенность: они, как правило, кажутся красивыми. «Чаще всего предполагают, что это связано с большей симметричностью суммарного портрета по сравнению с индивидуальными и нашими представлениями о «красивости» среднего» (Маурер, 2006: 9).

Русские, живущие в Коми-Пермяцком округе и испытывающие ежедневное влияние коми-пермяцкой культуры, чаще (52\%) выбирают коми-пермяцкое лицо, чем русские, не подверженные этому влиянию (42\%).

«Свое» лицо (стимул 1) русские из Коми-Пермяцкого округа выбирают почти в 6 раз реже $(8,7 \%)$, чем коми-пермяцкое $(52 \%)$, а коми-пермяки выбирают русское лицо в 3 раза чаще $(29 \%)$, чем сами русские.

Русские, не испытывающие регулярного влияния комипермяцкой культуры, выбирают «свое» лицо (стимул 1) в 2 раза чаще $(15 \%)$, чем русские из Коми-Пермяцкого округа, однако большинство (42\%) выбирает коми-пермяцкое лицо (стимул 3 ).

Таким образом, в экспериментальной группе коми-пермяков в выборе доминируют естественные лица (стимулы 1, 3); в контрольных группах русских предпочтение отдается «искусственному» (стимул 2) и коми-пермяцкому (стимул 3) лицам. 
Perception and Verbalization of Somatic (Bodily) Codes of Culture...

Итак, коми-пермяки воспринимают и узнают соматический код культуры: без особого труда определяют по внешнему виду «свое лицо», тогда как для русских эта информация часто остается «за кадром». Кстати, два коми-пермяка не выбрали «свое лицо», а выбрали русскую по причине: «с серьгами не надо», «эта лучше, она без серег», т.е. соматический природный код, по мнению комипермяков, не принимает искусственных элементов.

\section{Эксперимент 2. Вербализация соматического кода}

Далее респондентам предлагалось описать понравившуюся девушку (табл. 1). Всего дали характеристики 21 респондент комипермяков (23\%), получено 102 реакции. Русские респонденты предлагали лишь единичные реакции.

Таблица 1. Вербализация соматического кода: частотные реакции

\begin{tabular}{|c|c|c|c|}
\hline Реакции & $\begin{array}{c}\text { Стимул 1: } \\
\text { русская }\end{array}$ & $\begin{array}{c}\text { Стимул 2: } \\
\text { обобщенный } \\
\text { портрет }\end{array}$ & $\begin{array}{c}\text { Стимул 3: } \\
\text { коми-пермячка }\end{array}$ \\
\hline Количество реакций & 30 & 9 & 63 \\
\hline Единичные реакции & $\begin{array}{c}\text { яркая, } \\
\text { живая, } \\
\text { милая, } \\
\text { приятная, } \\
\text { позитивная, } \\
\text { счастливая } \\
\text { \% }\end{array}$ & $\begin{array}{c}\text { спортивная, } \\
\text { улыбка } \\
\text { красивая, } \\
\text { позитивная, } \\
\text { счастливая, } \\
\text { без сережек } \\
\%\end{array}$ & $\begin{array}{c}\text { смелая, нежная, } \\
\text { живая, сияющая, } \\
\text { яркая, счастливая, } \\
\text { любвеобильная, умная, } \\
\text { с хитрецой, позитивная } \\
\%\end{array}$ \\
\hline Веселая, жизнерадостная & 16.7 & - & 20,6 \\
\hline Добрая, доброжелательная & 10 & 22 & 14,3 \\
\hline Красивая, симпатичная & 13,3 & 22 & 14,3 \\
\hline Открытая, общительная & 3 & - & 9,5 \\
\hline Большеглазая, ясноглазая & 20 & - & 11 \\
\hline
\end{tabular}

По мнению коми-пермяков, «своя» девушка (коми-пермячка) более красивая, добрая, открытая, веселая и жизнерадостная, чем русская (таблица 1), однако «искусственная» девушка (стимул 2) признается коми-пермяками более красивой и доброй. «Своя» девушка получает большее разнообразие вербальных характеристик.

Анализ вербальных характеристик показал, что в оценках внешности всех лиц преобладают психологические характеристики (рис. 5), однако искусственно созданный образ практически не 
обладает «телесностью» (стимул 2 получает только одну условно соматическую характеристику без сережек).

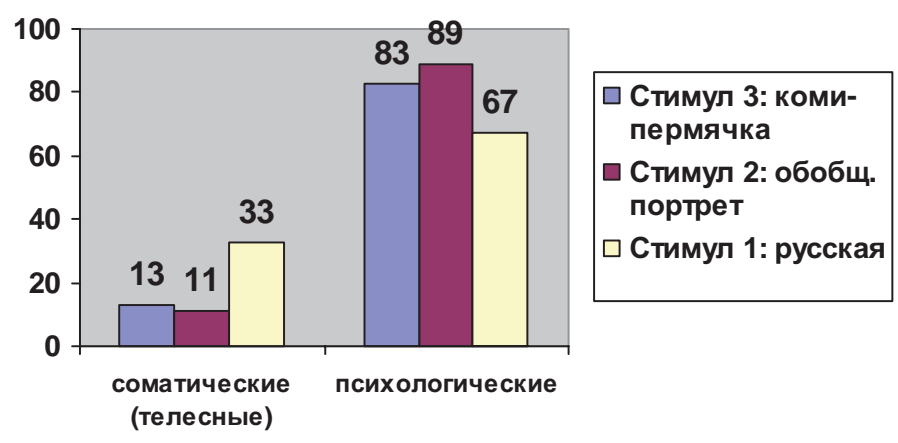

Рис. 5. Реакиฺии на стимул 1-3: коми-пермяки (\%)

Среди телесных характеристик респондентами для русской и коми-пермячки выделяются только глаза (большеглазая, ясноглазая, голубоглазая), румяность (обе девушки кажутся респондентам румяными). Для русской выделяются признаки светлая и круглолицая, хотя волосы всех девушек темного цвета.

Таким образом, в сознании коми-пермяков телесность преимущественно связана не с физическими, а психическими и нравственными характеристиками, которые и являются для комипермяков актуальными идентификаторами телесности.

\section{Выводы}

Эксперимент показал, что коми-пермяки хорошо идентифицируют этнический соматический код и не воспринимают искусственно созданную телесность, тогда как русские этническую соматику декодируют значительно реже и легко принимают искусственный усредненный типаж.

Несмотря на билингвизм и бикультурализм коми-пермяков в исторически полиэтничном регионе, этнос способен сохранять архетипически заданную соматику. Коми-пермяки больше ценят этнически близкий тип внешности, чем русские. Принципиальных гендерных предпочтений не выявляется.

Наш эксперимент показывает, что в сознании коми-пермяковбилингвов соматические коды культуры меняются медленнее, 
чем у русских. В контрольных группах русских прочтение и интерпретация кода представляют собой субъективный процесс и чаще зависят от личностного восприятия.

В сознании коми-пермяков телесность преимущественно связана не с физическими, а психическими и нравственными характеристиками, которые и являются для коми-пермяков актуальными идентификаторами телесности.

Перспективным полагаем исследование других кодов культуры (ландшафтно-природный, предметный, темпоральный $\quad$ и Необходимо также проведение повторного эксперимента с коррекцией стимульного материала (другие лица).

\section{Литература}

Аванесова, Г.А., Купцова, И.А. Коды культуры: понимание сущности, функциональная роль в культурной практике. $B$ мире науки и искусства: вопросы филологии, искусствоведения и культурологии. 2015. № 4 (47). С. 28-37. Новосибирск : СибАК.

Арутюнов, С.А. Билингвизм и бикультурализм. Советская этнография. 1978. № 2. C. 3-14.

Багаутдинова, Г.А. Человек во фразеологии: антропоцентрический и аксиологический аспекты : автореф. дисс. ... д-ра филол. наук : 10.02.20. Казань, 2007. 45 с.

Башкатова, Ю.А. Соматический код культуры как предмет сопоставительного исследования. Сибирский филологический журнал. 2014. № 4. С. 220-228.

Беликов, В.И., Крысин, Л.П. и др. Социолингвистика. Москва : Рос. гос. гуманит. ун-т, 2001. 439 с.

Вигель, Н.Л. Влияние билингвизма на культурные особенности. Психология, сочиология $u$ педагогика. 2017. № 2. URL : http://psychology.snauka. $\mathrm{ru} / 2017 / 02 / 7704$.

Выскочил, А.А. Этническая идентичность и межэтническое взаимодействие в Северной Башкирии : дис. ... канд. ист. наук : 07.00.07. Москва, 2005. 242 с.

Глоссарий. Социология в России / под ред. В.А. Ядова. Москва : Издательство Института социологии РАН, 1998. 696 с.

Горды, М. Соматическая фразеология современных русского и польского языков. Москва Горды - Щецин : Volumina.PL. 2010. 364 с.

Губогло, М.Н. Идентификация идентичности: Этносоциологические очерки. Москва : Наука, 2003. 764 с.

Гудков, Д.Б., Ковшова, М.Л. Телесный код русской культуры: материалы к словарю. Москва : Гнозис, 2007. 288 с.

Гудков, Д.Б. Единицы кодов культуры: проблемы семантики. Язык, сознание, коммуникаџия. 2004. Вып. 26. С. 39-50. Москва : МАКС Пресс.

Завалишина, К.Г. Концептосфера «человек телесный» в языке русского, немецкого и английского песенного фольклора : автореф. дисс. ... д-ра филол. наук: 10.02.01, 10.02.19. Курск, 2005. 20 с.

Кабакова, Г., Конт, Ф. От составителей. От русской души к русскому телу? Тело в русской культуре. Москва : Новое литературное обозрение, 2005. С. 5-16. 
Восприятие и вербализация соматических (телесных) кодов...

Красных, В.В. Коды и эталоны культуры (приглашение к разговору). Язык, сознание, коммуникачия. 2001. Вып. 19. С. 5-19.

Культурология. Часть 1 / С.В. Морозова, Л.В. Оржековская, Н.В. Якушкина [и др.] ; под ред. С.М. Прокопьева. Москва : МГУП, 2010. 248 с.

Леонтьева, Т.В. Интеллект человека в зеркале русского языка : автореф. дисс. ... канд. филол. наук : 10.02.01. Екатеринбург, 2003. 24 с.

Мазалова, Н.Б. Состав человеческий: человек в традиционных соматических представлениях русских. Санкт-Петербург : Петербургское востоковедение, 2001. 192 c.

Maypep, A.M. Обобщенный фотопортрет как источник антропологической информации : автореф. дисс. ... канд. биол. наук : 03.00.14. Москва, 2006. $30 \mathrm{c}$.

Попова, Н.Г. Проблемы этнической идентичности и межэтнического взаимодействия молодежи в полиэтничном пространстве сибирского города (по материалам анкетирования в Новосибирске). Вестник НГУ. Серия История. Филология. 2006. Т. 5. Вып. 3. С. 86-92.

Русских, Л.В. Мультикультурализм: интеграция или раскол? Вестник ЮжноУральского государственного университета. Серия: Социальногуманитарные науки». 2013. № 1. Т. 13. С. 174-176.

Симбирцева, Н.А. «Код культуры» как культурологическая категория. Знание. Понимание. Умение. 2016. URL : https://cyberleninka.ru/article/n/kod-kulturykak-kulturologicheskaya-kategoriya

Скоробогатая, А.А. Этническая идентичность и межкультурное взаимодействие в Северной Башкирии. Москва : ТЕИС, 2008. 190 с.

Толстая, С.М. К понятию культурных кодов. Studia Ethnologica. 2007. С. 23-31.

Толстой, Н.И, Толстая, С.М. О Словаре «Славянские древности». Славянские древности: этнолингвистический словарь / под ред. Н.И. Толстого : в 5 т. Москва : Международные отношения, 1995. Т. 1: А-Г. С. 5-14.

Чернышева, Е.Н. Глобальные культурные коды. Актуальные вопросы изучения мировой культуры в контексте диалога цивилизаций: Россия - Запад Восток : Материалы Международной научно-практической конференции «Славянская культура: истоки, традиции, взаимодействие. XVII КириллоМефодиевские чтения» (24 мая 2016 года). Москва ; Ярославль : Ремдер, 2016. C. 286-295.

Щирова, В.С. Немецкие соматические фразеологизмы как единицы этнокультурного кодирования. Тамбов : Изд-во ТРОО «Бизнес-НаукаОбщество», 2011. 205 с.

Эко, У. Отсутствующая структура. Введение в семиологию. ТОО ТК «Петрополис», 1998. 432 с.

Якушкина, Е.И. Анатомия стыда (этическая семантика соматизмов в славянских языках). Славянский вестник. 2003. Вып. 1. С. 96-105.

Giuseppina, A. (2017). Ethnic identity and scholastic effort: a multifaceted approach, IZA Journal of Development and Migration, 7 (2), 1-13. Retrieved from http:// dx.doi.org/10.1186/s40176-017-0088-0

Barth, F. (1969). Ethnic groups and boundaries: The social organization of culture difference. Boston: Little, Brown, \& Co.

Benet-Martínez, V., \& Haritatos, J. (2005). Bicultural Identity Integration (BII): Components and Psychosocial Antecedents. Journal of Personality, 73 (4), 1015 1049. DOI: $10.1111 /$ j.1467-6494.2005.00337.x 
Chandler, D. (1999). Semiotics for Beginners. URL: https://ru.scribd.com/ document/217104548/Daniel-Chandler-Semiotics-for-Beginners

Danesi, M. (2007). The Quest for Meaning: A Guide to Semiotic Theory and Practice. University of Toronto Press.

Geurts, K.L. (2002). Culture and the Senses: Bodily Ways of Knowing in an African Community. University of California Press. URL : http://www.jstor.org/ stable/10.1525/j.ctt1pnrfv

Csordas, T. (2002). Body. Meaning. Healing. New York: Palgrave.

Kyuchukov, H. (2016). Bilingualism and Cross-Cultural Study of Language and Cognitive Development. Psycholinguistics, 20 (1), 154-161

Olza Moreno, I. (2009) Aspectos de la semántica de las unidades fraseológicas. La fraseología somática metalingüística del español: Extended abstract of Doctor's thesis. Pamplona.

Phinney, J. (2003). Ethnic identity and acculturation. In K. Chun, P.B. Organista, \& G. Marin (Eds.), Acculturation: Advances in theory, measurement, and applied research (pp. 63-81). Washington, DC : American Psychological Association.

Root, M.P. (1992). Back to the drawing board: Methodological issues in research on multiracial people. In M.P. Root (Ed.), Racially mixed people in America (pp. 181-189). London : Sage Publications.

Sollars, W. (1996). Theories of ethnicity: A classical reader. New York : New York University Press.

Trimble, J.E. (2000). Social psychological perspectives on changing self-identification among American Indians and Alaska Natives. In R.H. Dana (Ed.), Handbook of Cross-Cultural and Multicultural Personality Assessment (pp. 197-222). Mahwah, NJ : Lawrence Erlbaum Associates.

Turner, B. (1984). The Body and Society. Oxford : Basil Blackwell.

Weinreich, P., \& Saunderson, W. (Eds.). (2003). Analyzing identity: Cross-cultural, societal and clinical contexts. New York : Routledge.

\section{References}

Avanesova, G.A., \& Kupcova, I.A. (2015). Kody kultury: ponimanie sushchnosti, funkcionalnaya rol $\mathrm{v}$ kulturnoj praktike [Codes of culture: understanding of essence, functional role in cultural practice]. $V$ mire nauki $i$ iskusstva: voprosy filologii, iskusstvovedeniya $i$ kulturologii - In the world of science and art: issues of Philology, art history and cultural studies, 4 (47), 28-37 [in Russian].

Arutyunov, S.A. (1978). Bilingvizm i bikulturalizm [Bilingualism and biculturalism]. Sovetskaya ehtnografiya - Soviet Ethnography, 2, 3-14 [in Russian].

Bagautdinova, G.A. (2007). Chelovek vo frazeologii: antropocentricheskij i aksiologicheskij aspekty [Man in phraseology: anthropocentric and axiological aspects]. Extended abstract of candidate's thesis. Kazan. [in Russian].

Bashkatova, Yu.A. (2014). Somaticheskij kod kultury kak predmet sopostavitelnogo issledovaniya [Somatic code of the culture as a subject of comparative study]. Sibirskij filologicheskij zhurnal - Siberian philological journal, 4, 220-228 [in Russian].

Belikov, V.I., \& Krysin, L.P. (2001). Sociolingvistika [Sociolinguistics]. Moscow : Ros. gos. gumanit. un-t [in Russian].

Vigel, N.L. (2017). Vliyanie bilingvizma na kulturnye osobennosti. Psihologiya, sociologiya i pedagogika - Psychology, sociology and pedagogy, 2. URL : http:// psychology.snauka.ru/2017/02/7704 [in Russian]. 
Восприятие и вербализаиия соматических (телесных) кодов...

Vyskochil, A.A. (2005). Etnicheskaya identichnost i mezhehtnicheskoe vzaimodejstvie $\mathrm{v}$ Severnoj Bashkirii [Ethnic identity and interethnic interaction in Northern Bashkiria]. Extended abstract of candidate's thesis. Moskow [in Russian].

Glossarij [Glossary] (1998). Sociologiya v Rossii - Sociology in Russia. Moskow : Izdatelstvo Instituta sociologii RAN [in Russian].

Gordy, M. (2010). Somaticheskaya frazeologiya sovremennyh russkogo i polskogo yazykov [Somatic phraseology of modern Russian and Polish languages]. Shchecin : Volumina.PL [in Russian].

Guboglo, M.N. (2003). Identifikaciya identichnosti: Ehtnosociologicheskie ocherki [Identification of identity: ethno-sociological essays]. Moskow : Nauka [in Russian].

Gudkov, D.B., \& Kovshova, M.L. (2007). Telesnyj kod russkoj kultury: materialy $k$ slovaryu [Corporal code of Russian culture: materials for the dictionary]. Moskow : Gnozis [in Russian].

Gudkov, D.B. (2004). Edinicy kodov kultury: problemy semantiki [Units of culture codes: problems of semantics]. Yazyk, soznanie, kommunikaciya - Language, consciousness, communication, 26, 39-50 [in Russian].

Zavalishina, K.G. (2005). Konceptosfera «chelovek telesnyj» v yazyke russkogo, nemeckogo i anglijskogo pesennogo folklora [Conceptual sphere «man corporal» in Russian, German and English song folklore]. Extended abstract of candidate's thesis. Kursk [in Russian].

Kabakova, G. (2005). Ot sostavitelej. Ot russkoj dushi k russkomu telu? [From the drafters. From the Russian soul the Russian body?], Telo v russkoj kulture Body in Russian culture (pp. 5-16). Moskow : Novoe literaturnoe obozrenie [in Russian].

Krasnyh, V.V. (2001) Kody i ehtalony kultury (priglashenie k razgovoru) [Codes and standards of culture (invitation to talk)]. Yazyk, soznanie, kommunikaciya Language, consciousness, communication, 19, 5-19 [in Russian].

Kulturologiya [Culturology], (Vol. 1) (2010). Moskow : MGUP [in Russian].

Leonteva, T.V. (2003). Intellekt cheloveka v zerkale russkogo yazyka [Human Intellect in the mirror of the Russian language]. Extended abstract of candidate's thesis. Ekaterinburg [in Russian].

Mazalova, N.B. (2001). Sostav chelovecheskij: chelovek v tradicionnyh somaticheskih predstavleniyah russkih [Composition human: man in traditional somatic representations of Russian]. Sankt-Peterburg : Peterburgskoe vostokovedenie [in Russian].

Maurer A.M. (2006). Obobshchennyy fotoportret kak istochnik antropologicheskoy informatsii [Generalized portrait as a source of anthropological information]. Extended abstract of candidate's thesis. Moskow [in Russian].

Popova, N.G. (2006). Problemy ehtnicheskoj identichnosti i mezhehtnicheskogo vzaimodejstviya molodezhi $\mathrm{v}$ poliehtnichnom prostranstve sibirskogo goroda (po materialam anketirovaniya $\mathrm{v}$ Novosibirske) [Problems of ethnic identity and interethnic interaction of youth in the polyethnic space of the Siberian city (based on the questionnaire survey in Novosibirsk)]. Vestnik $N G U-$ Bulletin of Novosibirsk state University. History. Philology, 5 (3), 83-92 [in Russian].

Russkih, L.V. (2013). Multikulturalizm: integraciya ili raskol? [Multiculturalism: integration or split?]. Vestnik Yuzhno-Uralskogo gosudarstvennogo universiteta. Seriya: Socialno-gumanitarnye nauki» - Bulletin of South Ural state University. Series: Social and human Sciences, 1 (13), 174-176 [in Russian]. 
Simbirceva, N.A. (2016). «Kod kultury» kak kulturologicheskaya kategoriya [«Code of culture» as a cultural category]. Znanie. Ponimanie. Umenie. - Knowledge. Understanding. Skill. Retrieved from https://cyberleninka.ru/article/n/kod-kulturykak-kulturologicheskaya-kategoriya [in Russian].

Skorobogataya, A.A. (2008). Ehtnicheskaya identichnost i mezhkulturnoe vzaimodejstvie $v$ Severnoj Bashkirii [Ethnic identity and intercultural interaction in Northern Bashkiria]. Moskow : TEIS [in Russian].

Tolstaya, S.M. (2007). K ponyatiyu kulturnyh kodov [The concept of cultural codes]. Studia Ethnologica - Studia Ethnologica. AB 60, 23-31 [in Russian].

Tolstoj, N.I. (1995). O Slovare «Slavyanskie drevnosti» [About the Dictionary «Slavic antiquities»]. Slavyanskie drevnosti: ehtnolingvisticheskij slovar - Slavic antiquities: ethnolinguistic dictionary, 1, 5-14 [in Russian].

Chernysheva, E.N. (2016). Globalnye kulturnye kody [Global cultural codes]. Slavyanskaya kul'tura: istoki, tradicii, vzaimodejstvie. XVII Kirillo-Mefodievskie chteniya - Slavic culture: origins, traditions, interaction. XVII of the Cyril and Methodius readings (pp. 286-295). Moskow; Yaroslavl : Remder [in Russian].

Shchirova, V.S. (2011). Nemeckie somaticheskie frazeologizmy kak edinicy ehtnokulturnogo kodirovaniya [German somatic phraseological units as units of ethno-cultural coding]. Tambov : Izd-vo TROO «Biznes-Nauka-Obshchestvo» [in Russian].

Eco, U. (1998). Otsutstvuyushchaya struktura. Vvedenie v semiologiyu [No structure. Introduction to semiology]. TOO TK «Petropolis». [in Russian].

Yakushkina, E.I. (2003). Anatomiya styda (ehticheskaya semantika somatizmov v slavyanskih yazykah) [Anatomy of shame (ethical semantics of somatisms in Slavic languages)]. Slavyanskij vestnik - Slavic Herald, 1, 96-105 [in Russian].

Giuseppina, A. (2017). Ethnic identity and scholastic effort: a multifaceted approach, IZA. Journal of Development and Migration, 7 (2), 1-13. Retrieved from http:// dx.doi.org/10.1186/s40176-017-0088-0

Barth, F. (1969). Ethnic groups and boundaries: The social organization of culture difference. Boston : Little, Brown, \& Co.

Benet-Martínez, V., \& Haritatos, J. (2005). Bicultural Identity Integration (BII): Components and Psychosocial Antecedents. Journal of Personality, 73 (4), 10151049. DOI: $10.1111 /$ j.1467-6494.2005.00337.x

Chandler, D. (1999) Semiotics for Beginners. Retrieved from https://ru.scribd.com/ document/217104548/Daniel-Chandler-Semiotics-for-Beginners

Danesi, M. (2007). The Quest for Meaning: A Guide to Semiotic Theory and Practice. University of Toronto Press.

Geurts, K.L. (2002). Culture and the Senses: Bodily Ways of Knowing in an African Community. University of California Press. URL: http://www.jstor.org/ stable/10.1525/j.ctt1pnrfv

Csordas, T. (2002). Body. Meaning. Healing. New York: Palgrave.

Kyuchukov, H. (2016). Bilingualism and Cross-Cultural Study of Language and Cognitive Development. Psycholinguistics, 20 (1), 154-161

Olza Moreno, I. (2009) Aspectos de la semántica de las unidades fraseológicas. La fraseología somática metalingüística del español: Extended abstract of Doctor's thesis. Pamplona.

Phinney, J. (2003). Ethnic identity and acculturation. In K. Chun, P.B. Organista, \& G. Marin (Eds.), Acculturation: Advances in theory, measurement, and applied research (pp. 63-81). Washington, DC : American Psychological Association. 
Восприятие и вербализаиия соматических (телесных) кодов...

Root, M.P. (1992). Back to the drawing board: Methodological issues in research on multiracial people. In M.P. Root (Ed.), Racially mixed people in America (pp. 181-189). London : Sage Publications.

Sollars, W. (1996). Theories of ethnicity: A classical reader. New York : New York University Press.

Trimble, J.E. (2000). Social psychological perspectives on changing self-identification among American Indians and Alaska Natives. In R.H. Dana (Ed.), Handbook of Cross-Cultural and Multicultural Personality Assessment (pp. 197-222). Mahwah, NJ : Lawrence Erlbaum Associates.

Turner, B. (1984). The Body and Society. Oxford : Basil Blackwell.

Weinreich, P., \& Saunderson, W. (Eds.). (2003). Analyzing identity: Cross-cultural, societal and clinical contexts. New York : Routledge.

\section{АННОТАЦИЯ}

Статья посвящена восприятию и вербализации соматических (телесных) кодов культуры в условиях билингвизма и бикультурализма. В условиях полевого эксперимента выявлялась способность коми-пермяковбилингвов идентифицировать соматические коды своей культуры. Эксперимент проводился в виде индивидуального анкетирования в Комипермяцком округе Пермского края РФ. Экспериментальный материал создавался при помощи метода обобщенного портрета. При помощи программы Face Morph друг на друга накладывались два изображения реальных девушек (коми-пермяцкой и русской). В результате было получено "искусственное» лицо, совмещающее соматику представителей двух не родственных индоевропейского и финноугорского этносов. Респондентам предъявлялись три изображения: русское, коми-пермяцкое и "искусственное» лица. Установлено, что коми-пермяки хорошо идентифицируют соматический код. В условиях билингвизма и бикультурализма в сознании коми-пермяков соматические коды культуры меняются медленнее, чем у русских. 62\% коми-пермяков выбирают лицо своего этноса. Менее всего комипермякам нравится "искусственное» лицо (9\% респондентов); 29\% коми-пермяков выбираю русское лицо. В контрольных группах русских интерпретация кода представляет собой субъективный процесс и чаще зависит от личностного восприятия. Русские в 4 раза чаще, чем комипермяки, выбирают "искусственное» лицо. Русские, постоянно живущие в Коми-Пермяцком округе, чаще (52\%) выбирают коми-пермяцкое лицо, чем русские, не подверженные ежедневному влиянию коми-пермяцкой культуры (42\%). "Свое» лицо русские из Коми-Пермяцкого округа выбирают в 6 раз реже (8,7\%), чем коми-пермяцкое (52\%), а комипермяки выбирают русское лицо в 3 раза чаще (29\%), чем сами русские. Русские, не испытывающие регулярного влияния коми-пермяцкой культуры, выбирают русское лицо в 2 раза чаще (15\%), чем русские из 
Коми-Пермяцкого округа, однако большинство (42\%) выбирает комипермяцкое лицо. Анализ вербальных реакций показал, что в сознании коми-пермяков телесность преимущественно связана не с физическими, а психическими и нравственными характеристиками, которые являются для коми-пермяков актуальными идентификаторами телесности.

Ключевые слова: билингвизм, соматический (телесный) код, код культуры, коми-пермяки, финно-угры, восприятие, этническая идентичность, этническая идентификация.

\section{Шляхова Світлана. Сприймання й вербалізація соматичних (тілесних) кодів культури в умовах білінгвізма}

\section{АНОТАЦІЯ}

Стаття присвячена висвітленню проблеми сприйняття й вербалізації соматичних (тілесних) кодів культури в умовах білінгвізма $і$ бікультуралізма. В умовах природного експерименту виявлялася здатність комі-пермяків-білінгвів ідентифікувати соматичні коди своєї культури. Експеримент проводився у вигляді індивідуального анкетування в Комі-Пермяцького окрузі Пермського краю РФ. Експериментальний матеріал створювався за допомогою методу узагальненого портрета. За допомогою програми Face Morph один на одного накладалися два зображення реальних дівчат (комі-пермяцької mа російської). В результаті була отримана "штучна» особа, що сполучає соматику представників двох неспоріднених індоєвропейських та фінно-угорських етносів. Респондентам пред'являлися три зображення: російська, комі-пермяцька і «штучна» особа. Встановлено, що комі-пермяки добре ідентифікують соматический код. В умовах білінгвізма і бікультуралізма в свідомості комі-пермяків соматичні коди культури змінюються повільніше, ніж у російських. 62\% комі-пермяків вибирають обличчя свого етносу. Найменше комі-пермякам подобається «штучна» особа (9\% респондентів); 29\% комі-пермяків вибирають російське обличчя. У контрольних групах російських інтерпретація коду являє собою суб'єктивний процес і частіше залежить від особистісного сприйняття. Росіяни в 4 рази частіше, ніж комі-пермяки, вибирають "штучну» особу. Росіяни, які постійно мешкають в Комі-Пермяцком окрузі, частіше (52\%) вибирають комі-пермяцьку особу, ніж російські, які не піддаються щоденного впливу комі-пермяцької культури (42\%). "Свою» особу росіян з Комі-Пермяцкого округу вибирають в 6 разів рідше (8,7\%), ніж комі-пермяцькому (52\%), а комі-пермяки вибирають російське обличчя в 3 рази частіше (29\%), ніж самі росіяни. Росіяни, які не відчувають регулярного впливу комі-пермяцькому культури, вибирають російську особу в 2 рази частіше (15\%), ніж росіяни з Комі- 
Восприятие и вербализация соматических (телесных) кодов...

Пермяцкого округу, проте більшість (42\%) вибирає комі-пермяцьку особу. Аналіз вербальних реакцій показав, що в свідомості коміпермяків тілесність переважно повязана не з фізичними, а психічними і моральними характеристиками, які $\epsilon$ для комі-пермяків актуальними ідентифрікаторами тілесності.

Ключові слова: білінгвізм, соматичний (тілесний) код, код культури, комі-пермяки, фріно-угри, сприйняття, етнічна ідентичність, етнічна ідентирікація. 